Tropical Journal of Pharmaceutical Research June 2012; 11 (3): 445-453

(C) Pharmacotherapy Group, Faculty of Pharmacy, University of Benin

Benin City, 300001 Nigeria.

All rights reserved.

Available online at http://www.tjpr.org

Research Article

http://dx.doi.org/10.4314/tjpr.v11i3.14

\title{
Artemisia Annua L. Infusion Consumed Once a Week Reduces Risk of Multiple Episodes of Malaria: A Randomised Trial in a Ugandan Community
}

\author{
Patrick E Ogwang ${ }^{1,3}$, Jasper O Ogwal ${ }^{4}$, Simon Kasasa ${ }^{2}$, Deogratius Olila ${ }^{3}$, \\ Francis Ejobi ${ }^{3}$, David Kabasa ${ }^{3}$ and Celestino Obua ${ }^{4^{*}}$ \\ ${ }^{1}$ Natural Chemotherapeutics Research Institute, Ministry of Health, P.O Box 4864, ${ }^{2}$ School of Public Health, College \\ of Health Sciences, Makerere University, PO Box 7072, Kampala, ${ }^{3}$ Faculty of Veterinary Medicine, Makerere \\ University, PO Box 7072, Kampala; ${ }^{4}$ Department of Pharmacology and Therapeutics, School of Biomedical Sciences, \\ College of Health Sciences, Makerere University, PO Box 7072, Kampala, Uganda
}

\begin{abstract}
Purpose: To evaluate the protective effect of Artemisia annua infusion against malaria in a community that uses it as herbal 'tea' for malaria prevention.

Methods: 132 flower farm workers who met the study inclusion criteria and were not yet using $A$. annua infusion were randomized either to $A$. annua or placebo groups in the ratio of 1:1. Treatments were administered once a week under direct observation to participants. Malaria episodes were documented over a 9-month period while adverse effects were documented over 12 months.

Results: A. annua herbal 'tea' significantly reduced the risk of suffering more than one episode of malaria in nine months by $55 \%$ (12/67 vs 26/65, $p=0.005$ No participant experienced any serious adverse effect although bitter taste was the most common side effect of the infusion.

Conclusion: Artemisia annua infusion consumed once a week was effective in preventing multiple episodes of malaria in humans living in malaria endemic areas. However, its bitter taste and the risk of development of malaria parasite resistance to the artemisinin contained in it remain major challenges for its use in the mass control of malaria.
\end{abstract}

Keywords: Artemisia annua, Herbal tea, Community, Malaria prevention 


\section{INTRODUCTION}

Artemisia annua is a medicinal plant used in traditional Chinese medicine in the treatment of febrile fevers, including malaria [1]. In 1972, artemisinin was isolated from A.annua as its most active antimalarial component [2]. Artemisinin and its synthetic derivatives form the major component of Artemisinin Combination Therapies (ACTs) which are the current WHO recommended first-line drugs for the treatment of uncomplicated malaria caused by Plasmodium falciparum[3-5]. Artemisinin and its metabolite, dihydroartemisinin, are highly active against malaria parasites, but they have very short plasma half-life [6]. The short half-life makes them unsuitable for malaria prevention and are probably less prone to the development of resistance against them by the parasite.

In Uganda, $A$. annua is being used by some communities as a herbal tea, taken once a week for malaria prevention and for other illnesses such as HIVIAIDS [7]. The effectiveness and safety of the tea when used in malaria prevention remain unknown. This study was, therefore, designed to evaluate the protective effect of A.annua against malaria in a community that uses it as a 'tea' for malaria prevention, and to predict its mode of action in the claimed prophylaxis.

\section{EXPERIMENTAL}

\section{Collection and processing of Artemisia annua and Thea sinensis dry leaf powders}

Artemisia annua used by the farm workers in the first 8 months of the study was sourced from the farm garden and when it was out of stock by the $9^{\text {th }}$ month, the farm purchased it from a commercial source..Artemisinin content in $A$. annua dry leaves from the farm ranged from $0.4-0.5 \%$ while for the commercial source, it was $0.8 \%$. The concentration of artemisinin in the infusion made from farm-derived $A$. annua was 0.055 $\mathrm{mg} / \mathrm{ml}$ while for the commercial one, it was $0.100 \mathrm{mg} / \mathrm{ml}$. Thea Sinensis( tea leaves) powder used as placebo in the study was purchased from the local market near the study site. A. annua from the farm garden was collected in February 2009 and identified by $M$ Nusula of Natural Chemotherapeutics Research Institute. A voucher specimen NCJ 257 was deposited at the herbarium of Natural Chemotherapeutics Research Institute, Ministry of Health, Uganda.

\section{Study site}

The study was conducted in Wagagai flower farm located on the shores of Lake Victoria in Entebbe, about $35 \mathrm{~km}$ south of Kampala, the capital city of Uganda. Wagagai flower farm was founded in 1998 by Dutch investors and it exports flowers to Europe. A. annua use for malaria prevention was initiated by the farm management in 2006 with about 80 workers and by the time of this study about 600 of 1500 workers were using it (Wagagai farm records, unpublished). The flower farm has a well-equipped health centre that serves the farm workers and neighbouring community. The outpatient clinic records indicated that malaria accounted for $30 \%$ of outpatient hospital attendance, which falls within national figures of $25-40 \%$ reported by the Ministry of Health [8]. However, by the time this study was initiated among the farm workers, malaria accounted for between 16 $20 \%$ of outpatient attendance (Wagagai clinic record, 2009 unpublished).

\section{Standardisation of Artemisia annua 'tea'}

We standardised $A$. annua infusion used for malaria prophylaxis based on the practice in the farm. Standardised $A$. annua infusion was equivalent to $20 \mathrm{mg} / \mathrm{ml}$ (dry leaf powder) prepared by adding boiling water to A.annua powder, stirred and allowed to infuse for 30 min, sieved and served immediately. In our study, honey was added to improve taste. The content of artemisinin in leaf powder and in the infusion of A. annua were determined at three time points - April, June and December 2009 using a standard high 
pressure thin layer chromatography method [9].

In administering the tea, each participant in the $A$. annua group received a dose equivalent of $250 \mathrm{ml}$ infusion (containing $5 \mathrm{~g}$ dry powder), which was consumed at once every Wednesday under direct observation by the study nurse. The control group received equivalent volume of $T$. Sinensis which also had equivalent volume of honey as that used in $A$. annua infusion.

\section{Sample size determination}

The study was designed to have a statistical power of $80 \%$ and to detect a $60 \%$ difference at a significant level of 0.05 based on the national outpatient malaria incidence of $40 \%$. The design required ninety eight (98) participants randomised to either $A$. annua or placebo groups in the ratio of $1: 1$ [10]. We recruited all the 132 participants who turned up after screening in order to take care of the anticipated dropout rate due to high labour turnover in this farm and also lower malaria burden among the farm workers than had been used in sample size determination (Wagagai Farm records, unpublished).

\section{Study subjects screening}

One hundred and seventy one (171) newly recruited adult farm workers who were not yet on $A$. annua prophylaxis registered to participate and were screened for the study. Eligibility criteria for a participant were; history of at least 2 episodes of malaria in a year, no use of malaria prevention medication or drugs or herbs before or during the study period other than those in the study, passed physical examination, Giemsa stain blood smears negative for malaria parasites, normal organ functions including renal, hepatic and haematological and human chorionic gonadotropin (pregnancy) test negative for females.

\section{Randomisation and blinding}

The volunteers with no malaria parasites in the blood smears (Giemsa technique) who met eligibility (inclusion) criteria were randomised in the ratio of $1: 1$ to either Artemisia or placebo groups previously assigned as odd and even, respectively. A participant picked, without replacing, from a box a number written on folded paper to determine his or her group (see Table 1 and Figure 1)

\section{Monitoring of study participants}

Study participants were monitored for episodes of malaria over nine months (April to December 2009) instead of planned 12 months because from month 8 to 9 , no cases of malaria occurred in $A$.annua group. Giemsa stain (hin and thick) microscopy technique [11] was used to detect malaria parasites in blood while polymerase chain reaction (Gene AMP, PCR system model 9700, Apllied Biosystems) was used for speciation and quality control of microscopy. Malaria episode was defined as presence of signs and symptoms of malaria (fever, headache, joint pain or bitter taste) plus blood smear with $>0$ parasites. The number of participants with no clinical malaria but carrying parasites in their blood was determined after months 3 and 6 of prophylaxis. Parasitaemia was checked independently by two experienced laboratory technicians and where variation was observed a third laboratory technician examined the slides. Occurrence of serious adverse effects was monitored over 12 months through weekly self-report by the participants and monthly clinical examination by the study physician in addition to the biochemical and haematological tests. The clinical signs looked for include: skin rash, jaundice, changes in blood pressure and heart rate, and were documented for each participant. Female participants who missed their menses had pregnancy test done and those found positive were counseled and excluded from the study. Study participants 


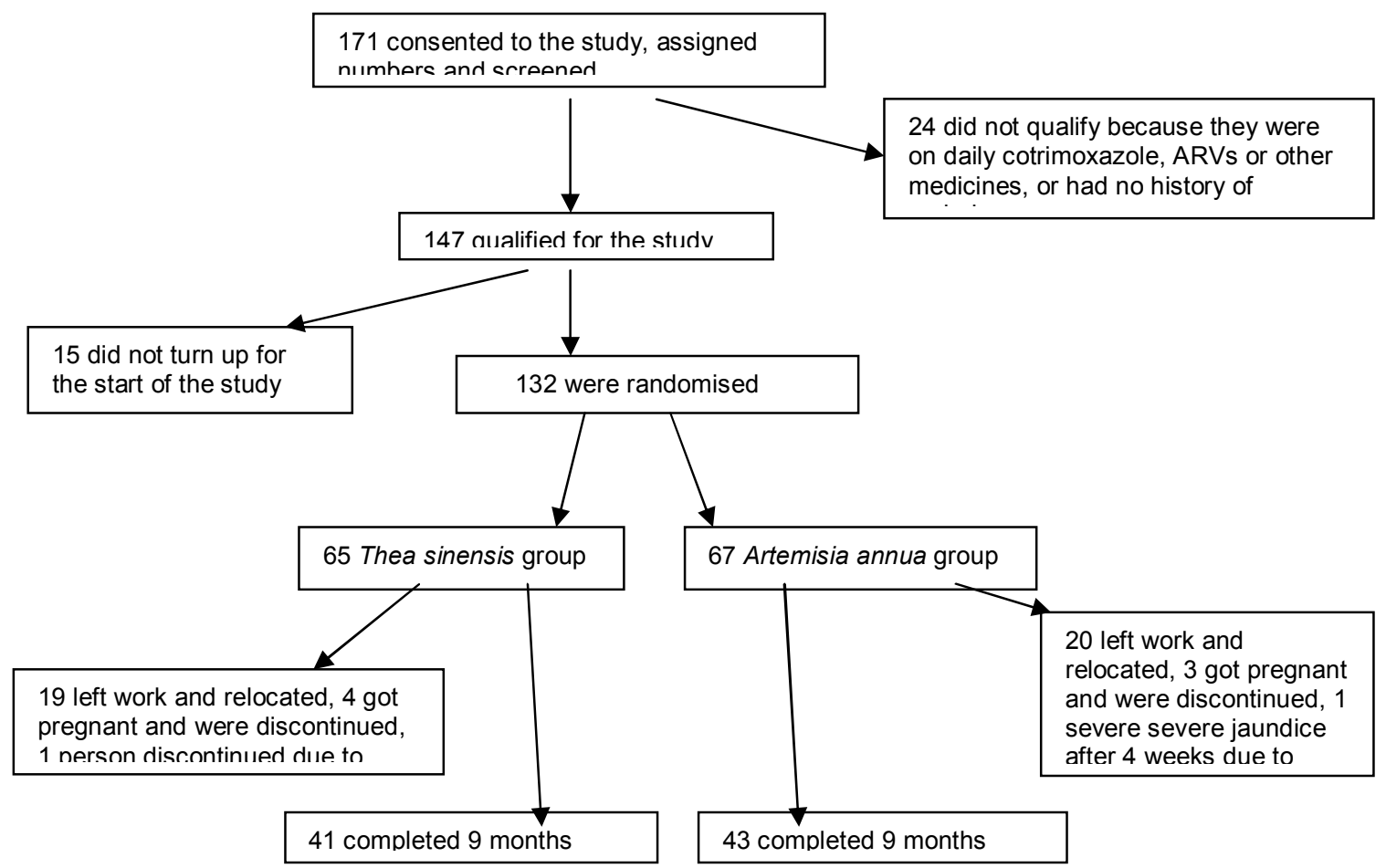

Figure 1: Participants' recruitment, enrolment and follow up chart

Table 1: Study participants' demographic/baseline data

\begin{tabular}{llll}
\hline Descriptive statistics & Artemisia (n= 67) & Control (n=65) & $P$-value \\
\hline Sex: $\quad$ Female & $38(56.7 \%)$ & $39(58.3 \%)$ & 0.702 \\
& $29(43.3 \%)$ & $26(41.7 \%)$ & \\
Marital status: & & & \\
$\quad$ Single & $25(37.3 \%)$ & $28(43.1 \%)$ & 0.561 \\
$\quad$ Not stated & $32(47.8 \%)$ & $31(47.7 \%)$ & \\
Bed net use: $\quad$ Yes & $10(14.9 \%)$ & $6(9.2 \%)$ & \\
$\quad$ No & $24(35.8 \%)$ & $12(18.5 \%)$ & 0.025 \\
Mean age (years) & $43(64.2 \%)$ & $53(81.5 \%)$ & \\
Mean temperature $\left({ }^{\circ} \mathrm{C}\right)$ & $26.6 \pm 6.4$ & $25 \pm 4.3$ & 0.100 \\
Average weight (kgs) & $36.7 \pm 0.5$ & $36.7 \pm 0.5$ & 0.78 \\
Haemoglobin(g/dl) & $56.3 \pm 6.4$ & $54.7 \pm 6.1$ & 0.15 \\
White Blood cell x 1000/mm & $14.2 \pm 1.8$ & $14.6 \pm 1.6$ & 0.35 \\
Creatinin level (ummol/L) & $5.8 \pm 2.0$ & $5.7 \pm 2.0$ & 0.93 \\
Alanine aminotransferase (IU/L) & $99.4 \pm 15.5$ & $95.5 \pm 17.0$ & 0.15 \\
\hline
\end{tabular}

With the exception of bednets, the randomisation ensured equal distribution of participants' characteristics between the groups. The effect of bednets on in the incidence of malaria was accounted for in the analysis. 
Table 2: Distribution of clinical malaria between Artemisia and placebo groups over a 9-month period

\begin{tabular}{lllllll}
\hline Episodes & $\begin{array}{l}\text { Artemisia } \\
\%(\mathrm{n})\end{array}$ & $95 \% \mathrm{Cl}$ & $\begin{array}{l}\text { Placebo } \\
\%(\mathrm{n})\end{array}$ & $95 \% \mathrm{Cl}$ & $\mathrm{Z}$ & $\mathrm{P}$ \\
\hline 0 & $53.7(36)$ & $42.1,65.9$ & $35(23)$ & $23.4,46.6$ & 2.2 & $0.028^{*}$ \\
1 & $28.4(19)$ & $17.2,38.8$ & $25 \%(16)$ & $14.5,35.5$ & 0.4 & 0.696 \\
2 & $13.4(9)$ & $5.0,21.0$ & $28(18)$ & $17.1,38.9$ & -2.14 & $0.032^{*}$ \\
3 & $3.0(2)$ & $-1.1,7.1$ & $11(7)$ & $3.4,18.6$ & -1.81 & 0.071 \\
4 & $1.5(1)$ & $-1.3,5.3$ & $1.5(1)$ & $-1.4,5.5$ & 0.00 & 1.000 \\
$>1$ & $17.9(12)$ & $8.8,27.2$ & $40(26)$ & $28.1,51.9$ & -2.79 & $0.005^{*}$ \\
\hline
\end{tabular}

*Artemisia annua infusion had a significant protective effect against malaria especially in reducing multiple episodes of malaria.

A signed written consent was obtained from each study participant and filed appropriately. Written permission to conduct study in Wagagai Flower Farm and publish the findings was granted by the farm's management. The study was approved by the Makerere University Institutional Review Board and permission to conduct study was granted by the Uganda National Council for Science and Technology (UNCST) under protocol registration number HS 528 .

\section{Data management and analysis}

All data were captured into participants' case report and laboratory forms at the study sites. Participants' files were then transported at the end of data collection to the central office for data entry and further management. Double data entries were done in Epidata (version 3.1), with pre-designed check programs for quality control, and in Microsoft Excel 2007 as backup. The data were then exported to Stata, version 9.0, for cleaning and analysis. The risk of first and multiple episodes of malaria were determined by intention-to-treat (ITT) approach using a two sample proportion analysis in Stata. Malaria incident rate reduction (protection efficacy) was determined by per protocol using Poisson regression model for rates computed in person-months. Haematological and biochemical data was compared using paired Student's t-test and only significant data are reported. Study participants' demographic and baseline data were compared between the groups using Chi-square and paired Student's t-tests. All data were analysed at
$95 \%$ confidence interval and a difference was considered statistically significant if $p<$ 0.05 .

\section{RESULTS}

Effect of $A$. annua tea on clinical and subclinical malaria

A total of 124 episodes of malaria were recorded over a period of nine months with $88.8 \%$ being infections caused by Plasmodium falciparum. The effect of $A$. annua infusion on malaria episodes is shown in Table 2.

Malaria incidence rate, protection efficacy of $A$. annua 'tea' and effect of mosquito bednets

The average follow-up time for malaria incident rate was $7.4 \pm 2.4$ months for the Artemisia group and $6.9 \pm 3.0$ months for the placebo. Malaria incident rate was $10 \%$, $(95 \% \mathrm{Cl} 7.5,13.5)$ person months and $16 \%$ $(95 \% \mathrm{Cl} 12.5,19.5)$ person months for Artemisia and placebo groups, respectively giving protection efficacy of $37.5 \%$ ( $p=$ 0.015). Comparison of malaria incidence rate reduction in participants with no mosquito bed nets showed a similar protective effect of $38.4 \%, p=0.03$. bednets use had a non significant effect of $26.7 \%,(p=0.41)$ in participants who used both $A$. annua and bednets. The malaria protective effect of the $A$. annua infusion showed increasing trend in Chi square test for trend $(p=0.003)$ with no cases of clinical malaria occurring in the 


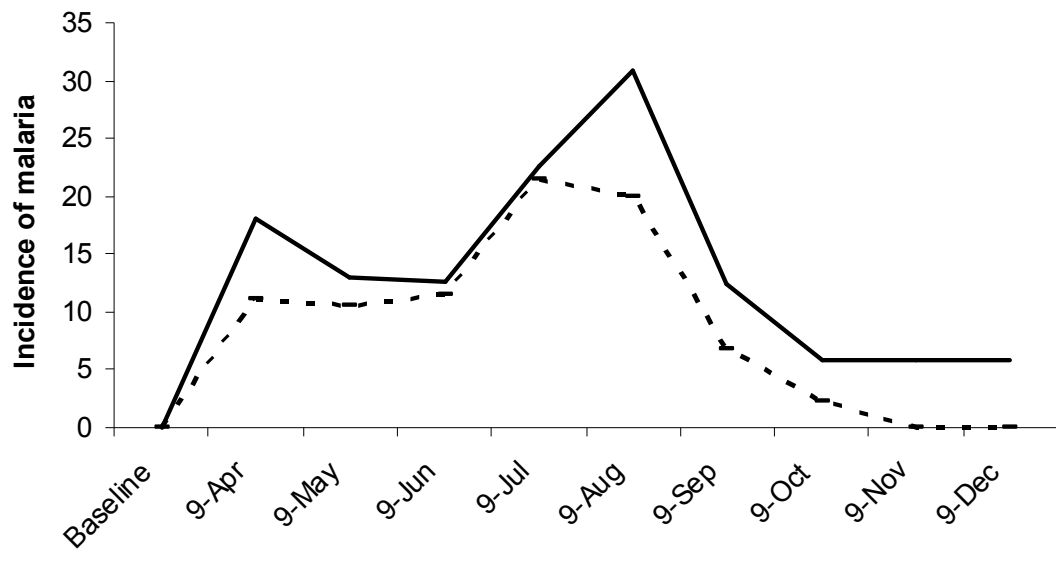

Time of the year

Figure 2: Monthly incidence of malaria in Artemisia (dashed line) and placebo (unbroken line) groups

Artemisia group by the Month 8 of prophylaxis (Figure 2).

\section{Effect of $A$. annua tea on parasite carriage and white blood cells}

Malaria parasites (sub-clinical malaria) in participants in $A$. annua group were reduced by more than $60 \%$ by months 3 and 6 of prophylaxis with the infusion. These participants also had higher white blood cell count than those on placebo (see Table 3).

\section{Adverse effects of $\boldsymbol{A}$. annua tea}

Although bitter taste was a major side effect, none of the participants on A.annua experienced any serious adverse clinical or systemic effects associated with it. One participant on $A$. annua infusion, however, presented with severe jaundice after 4 weeks of prophylaxis. Laboratory investigation revealed hepatitis $B$ as the cause of the jaundice. The participant was thereafter excluded from the study and treated; the participant recovered in six weeks.

Table 3: White blood cells levels in participants on $A$. annua and control groups

\begin{tabular}{llllll}
\hline $\begin{array}{l}\text { Blood sampling } \\
\text { time }\end{array}$ & $\begin{array}{l}\text { Diagnostic } \\
\text { marker }\end{array}$ & $\begin{array}{l}\text { Artemisia group } \\
\text { Mean } \pm \text { SD }(\mathrm{n})\end{array}$ & $\begin{array}{l}\text { Control group } \\
\text { Mean } \pm \text { SD }(\mathrm{n})\end{array}$ & $\begin{array}{l}\text { Difference } \\
\text { (t value) }\end{array}$ & $\mathrm{p}$ value \\
\hline At baseline & T.WBC & $5.76 \pm 1.94(47)$ & $5.72 \pm 2.02(49)$ & 0.0899 & 0.9286 \\
& Lymphocytes & $2.45 \pm 0.96(47)$ & $1.95 \pm 0.83(49)$ & 1.65 & 0.1023 \\
& Monocytes & $0.67 \pm .68(47)$ & $0.70 \pm 0.50(49)$ & -0.20 & 0.844 \\
At 3 months & Granulocytes & $2.84 \pm 1.21(47)$ & $3.29 \pm 1.43(49)$ & -1.53 & 0.1306 \\
& T.WBC & $5.80 \pm 1.77(33)$ & $6.05 \pm 2.36(44)$ & -0.52 & 0.606 \\
& Lymphocytes & $2.37 \pm 0.74(33)$ & $2.35 \pm 1.08(44)$ & 0.084 & 0.933 \\
& Monocytes & $0.54 \pm 0.47(33)$ & $0.72 \pm 0.59(44)$ & -1.47 & 0.145 \\
At 6 months & Granulocytes & $2.89 \pm 1.54(33)$ & $3.00 \pm 1.19(44)$ & -0.34 & 0.737 \\
& T.WBC & $5.26 \pm 1.51(39)$ & $4.71 \pm 1.47(43)$ & 1.71 & $0.046^{*}$ \\
& Lymphocytes & $2.14 \pm 0.72(39)$ & $1.98 \pm 0.58(43)$ & 1.13 & 0.135 \\
& Monocytes & $0.49 \pm 0.29(39)$ & $0.39 \pm 0.18(43)$ & 1.91 & $0.029^{*}$ \\
& Granulocytes & $2.66 \pm 1.03(39)$ & $2.34 \pm 1.04(43)$ & 1.39 & 0.084 \\
& T.WBC & $6.00 \pm 1.75(36)$ & $5.21 \pm 1.46(39)$ & 2.12 & $0.0187^{*}$ \\
& Lymphocytes & $2.67 \pm 0.89(36)$ & $2.27 \pm 0.74(39)$ & 2.14 & $0.0179^{*}$ \\
& Monocytes & $0.93 \pm 0.42(36)$ & $0.78 \pm 0.29(39)$ & 1.85 & $0.034^{*}$ \\
& Granulocytes & $2.41 \pm 1.30(36)$ & $2.17 \pm 0.92(39)$ & 0.94 & 0.174 \\
\hline
\end{tabular}

Once a week dose of A.annua significantly elevated the levels of monocytes by the $6^{\text {th }}$ months of prophylaxis 


\section{DISCUSSION}

In this study, by using a randomised trial design, we established that $A$.annua herbal tea (leaf infusion), equivalent to $5 \mathrm{~g}$ in $250 \mathrm{ml}$ $(20 \mathrm{mg} / \mathrm{ml})$, taken once a week at Wagagai Flower Farm in Uganda has a protective effect against malaria. It is especially effective in reducing the risk of having multiple episodes of malaria in an individual living in a malaria-endemic setting. In Uganda, it is estimated that on the average, an individual suffers between 3 and 6 episodes of malaria in a year if he/she is not using insecticide-treated nets [8]. In this study, $17.9 \%$ of the participants using $A$. annua suffered more than one episode of malaria compared to $40 \%$ in the placebo group and also had statistically significant reduction in malaria incident rate when adjusted and not adjusted for bednet use.

The use of $A$. annua in this farm benefited not only the farm workers through reduced incidence of malaria, reduced hospital visits and expenditure on treatment but also the farm management of the farm through increased staff productivity. Although $A$. annua can grow well in most parts of Uganda and is effective in preventing the risk of multiple episodes of malaria, the infusion used in this study community however a bitter taste had and also contained artemisinin. These two elements are a major limitation to mass use in Uganda and other communities. The use of A.annua infusion containing artemisinin hightens the risk of development of malaria parasites resistant to artemisinin and related drugs.

The low levels of artemisinin in the infusion, however, indicate the unlikely role of artemisinin in the observed protective effect against malaria. It is probable that the antimalarial and immune-modulating group of flavonoids, previously reported to be present in $A$. Annua, may be responsible for the prophylactic effect of the infusion. This is buttressed by the fact that participants took the treatment once a week, and usually within
$24 \mathrm{~h}$ of oral administration of artemisinin, almost all of it and its metabolite (dihydroartemisinin) are eliminated from the body [6].

Previous in vitro studies of $A$. annua flavonoids, especially casticin, cirsillineol, chrysosplenol D, chrysosplenetin and artemetin, have shown that these compounds also have powerful immunomodulatory activities [13-14,15]. In this study, participants who took $A$. annua infusion demonstrated both lower risk of malaria attack and higher levels of monocyte blood cells than the placebo group. Monocytes, have been documented to phargocytocize human erythrocytes infected by Plasmodium falciparum malaria parasites at a rate of 7.5 and 2.9 permonocyte for erythrocytes containing young and mature parasites, respectively, compared to 0.8 per monocyte for non-infected erythrocytes [16]. Monocytes have also been shown to play an important role in blood stage malaria in mice [17]. The increase in monocyte count was not transient as levels remained significant from the 6th month of prophylaxis even when no cases of malaria occurred in the A.annua group from the 8th month. The effect of $A$. annua flavonoids as both antimalarial and immune modulator may, therefore, explain the observed prophylactic effect of $A$. annua against malaria; however, this can only be proved in a study that uses $A$. annua tea that does not contain artemisinin. Since immune suppression and malnutrition have been documented as major risk factors for malaria, cancers and other diseases in sub-Saharan Africa, this study reveals the potential use of $A$. annua for the control of malaria and other burdensome diseases in Africa.[16,18-20]. Combining $A$. annua flavonoids with locally available nutritional products may provide hope for affordable and effective means of combating malaria.

\section{CONCLUSION}

$A$. annua infusion consumed once a week as a herbal tea is effective in preventing multiple 
episodes of malaria attacks and its mode of action may involve stimulation of white blood cells production especially monocytes.

\section{ACKNOWLEDGEMENT}

Special thanks go to Mrs Marion Boenders who is in-charge of Wagagai Health Centre, and the staff of Wagagai for allowing our team to use the farm community and health facilities during this study; same goes to the volunteers for their cooperation throughout the study period. Our appreciation goes to the staff of Natural Chemotherapeutics Research Laboratory, Ministry of Health, Faculty of Veterinary Medicine, Makerere University, and Addis Ababa University, Ethiopia, for providing facilities and technical support for this work. The Carnegie Corporation, through Rise-Afnnet Makerere node, and the Government of Uganda, through the Presidential Support to Scientists, are gratefully acknowledged for financial support.

\section{REFERENCES}

1. Willcox $L M$, Bodeker G. Traditional medicines for malaria. Brit Med J 2004; 329: 1156-1159.

2. Guoqing Z, Yayi G, Bin Z, Song W, Linhua T. No PfATPase6 S769N mutation found in Plasmodium falciparum isolates from China. Malaria Journal 2008; 7: 122

3. Lyda O, Iveth G, Piero O, Walter RJT. Artemisininbased combination therapy for Uncomplicated Plasmodium falciparum malaria in Colombia. Malaria Journal 2007; 6(2): 1-9

4. Sinclair D, Zani B, Donegan S, Olliaro $P$, Garner $P$. Artemisinin-based combination therapy for treating uncomplicated malaria. Cochrane Database of Systematic Reviews 2009; Issue 3. Art. No.: CD007483. Published online DOI: 10.1002/14651858.CD007483.pub2

5. Dorsey G, Staedke S, Clark TD, Njama-Meya D, Nzarubara B, Maiteki SC, Dokomajilar C, Kamya MR, Rosenthal PJ. Combination therapy for uncomplicated falciparum malaria in Ugandan children; a randomized trial. JAMA 2007; 297(20): 2210-2219

6. Rath K, Taxis K, Walz G, Gleiter CH, Li S,Heide L. Pharmacokinetic study of Artemisinin after Oral intake of traditional Preparation of Artemisia annua L.Am. J Tropical Medicine \& Hygiene 2004; 70(2): 128-132.
7. Ogwang PE, Ogwal-Okeng J, Kasasa S, Ejobi F, Kabasa D, Obua C: Use of Artemisia annua $L$. Infusion for Malaria Prevention: Mode of Action and Benefits in a Ugandan Community. British J. Pharm. Res 1(4): 124-132, 2011

8. Ministry of Health Uganda's Malaria Control Strategic Programme (UMCSP) report 20022005.

9. Agarwal SP, Ali A, Dua Y, Ahuja S: Determination of artemisinin in bulk and Pharmaceutical dosage forms using HPTLC. Indian J Pharm Sci 2009; 71: 98-100

10. Fleiss JL. Statistical methods for rates and proportions. 2nd ed, New York: John Wiley, 1981, pp 38-46.

11. Makler MT, Palmer CJ, Ager AL. A review of practical techniques for the diagnosis of malaria. Ann Trop Med Parasitol 1998; 92: 419-433.

12. World Medical Organization. Declaration of Helsinki. British Medical Journal (7 December) 1996;313(7070):1448-1449.

13. Bilia A, de Malgalhaes PM, Bergonzi M, Vincieri F. Simultaneous analysis of artemisinin and flavonoids of several extracts of Artemisia annua $L$. obtained from a commercial sample and a selected cultivar. Phytomedicine 2006; 13(7): 487-493

14. Liu CK, Yang SL, Roberts MF, Elford BC, Phillipson JD. Antimalarial activity of Artemisia annua flavonoids from whole plants and cell cultures. Plant Cell Reports 1992; 11(12): 637-640

15. Bhakuni RS, Jain DC, Sharma RP. Phytochemistry of Artemisia annua and the development of artemisinin-derived antimalarial agents. In Artemisia, Wright, C.W., Ed. Taylor \& Francis, London 2002; pp 211-248.

16. Turrini F, Ginsburg H, Bussolino F, Pescarmona GP, Serra MV, Arese P. Phagocytosis of Plasmodium falciparum-infected human red blood cells by human monocytes: involvement of immune and nonimmune determinants and dependence on parasite developmental stage. Blood 1992; 80: 801-808

17. Sponaas $A M$, Rosario AP, Voisine $C$, Mastelic $B$, Thompson J, Koernig Sandra, Jarra W, Renia L, Mauduit M, Potocnik AJ, Langhorne J. Migrating monocytes recruited to the spleen play an important role in the control of blood stage malaria. Blood 2009, 114: 5522-5531

18. Jorge FSF, Devanand LL, Tomikazu S, Arne $H$. Flavonoids from Artemisia annua $L$. as Antioxidants and their Potential Synergism with Artemisinin against Malaria and Cancer (Review). Molecules 2010; 15: 3135-3170

19. Adele ML, Kevin JS. Common dietary flavonoids inhibit the growth of the intraerythrocytic malaria parasite. BMC Res Notes 2008; 1: 26. Published online 2008 June 18. doi: 10.1186/1756-0500-1-26.

20. Elford BC, Roberts MF, Phillipson JD, Wilson RJ. Potentiating of the antimalarial activity of 
Ogwang et al

ginghaosu by methylated flavones.Trans $R$ Soc Trop Med Hyg. 1987; 81(3): 434-436 